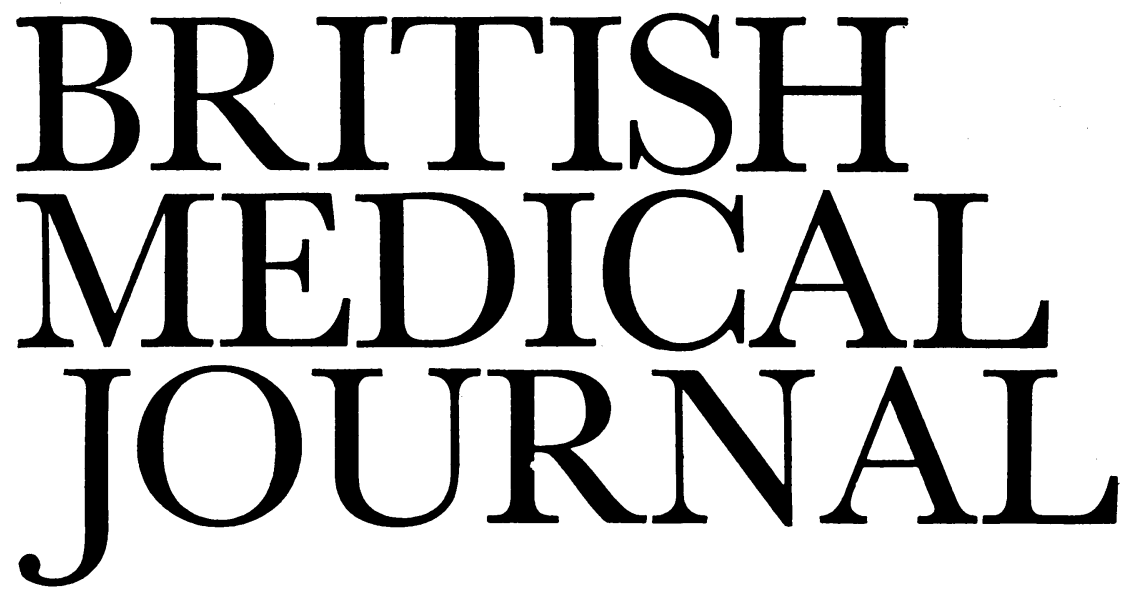

\title{
Death by a thousand cuts
}

"There is nothing more to be done for your mother," says the registrar to the anxious son, "but we shall keep her comfortable." Increasingly often that reassurance is a well-intentioned lie. More could be done if the NHS provided the same calibre of modern treatment (for renal failure, heart disease, arthritis) as Germany, France, Italy, or the United States. ${ }^{1}$ Most NHS patients are also denied access to recent innovations (nuclear magnetic resonance, radioisotope imaging, two-dimensional ultrasound) which have made clinical investigation safer, less distressing, and more accurate for those lucky enough to be seen in well-equipped centres of excellence. ${ }^{2}$

Indeed, without centres of excellence around the country the NHS might be less aware of the growing gap between the care of patients in most hospitals and what is possible in a fully staffed, fully equipped academic unit. Hence all clinicians should be concerned about the threat to standards from the current financial problems in academic medicine. For six months the universities have been struggling to balance their budgets after the cuts imposed by the Government through the University Grants Committee. At the recent joint BMA/ BDA conference on medical education ${ }^{3}$ several academics forecast catastrophe within 12 months if more money is not found. Postgraduate institutions have been hit especially hard by the Government's decision to charge overseas students economic fees. The Royal Postgraduate Medical School announced last month that since 1974 it has been forced to "freeze" 22 academic posts and 61 others. It will have to disestablish a further eight medical posts at consultant level, four non-clinical academic staff posts, and 22 posts in other categories-and yet it still faces a massive deficit in 1982-3. The further reductions that would be necessary to balance the books would "severely damage" the school's effort in medical research or curtail clinical services to Hammersmith Hospital.

A sharp drop in their income has combined with continuing inflation and the high costs of redundancy payments to force universities into a policy of not replacing staff who retire or leave. The distortions produced by this random attrition will take years to correct-and it is proving especially damaging in medical schools, with their traditional high rate of turnover in junior academic staff. Inevitably, cuts in departments with heavy clinical commitments are exacerbating the problems of the NHS ; as Sir John Walton told the conference last month, ${ }^{3}$ cracks are appearing in the structure of the agreement whereby university staff treat patients and NHS staff teach-without money changing hands.

Like most financial crises, the universities' plight has been building up for years-and a whole chorus of Cassandras has given repeated warnings. For too long the universities have patched and made do, like an elderly couple in a house too big for its financial resources, in the hope that something would turn up. The time has come for them to face reality. If academic standards are to be maintained, radical solutions are needed. The current policy of random redundancies and economies must lead to a downward spiral of low morale and mediocrity. Nor can hard-pressed departmental heads be expected indefinitely to devote their time and energy to a search for outside funding.

Several solutions have been canvassed and must now be re-examined with greater urgency. Firstly, some universities (and some medical schools) could and, the $B M F$ believes, should be shut. The University of London allowed the Flowers proposals $^{4}$ for amalgamations and fusions of the medical schools in London to be talked to death; little overt progress has been made. ${ }^{5}$ Closures are feasible in London; two schools could go out of the 12 . Outside London the new medical schools, such as Nottingham, which were set up in disadvantaged areas are deeply resentful of the problems they are now facing; but again one or perhaps two provincial medical schools (not necessarily the newest ones and both not necessarily in England) may need to be closed if the quality of medical education is to be maintained. Possibly also one medical school could be converted to a private sector institution on the lines of the University of Buckingham.

Need every teaching institution be linked with academic research? In the United States some universities simply teach undergraduates. Might not British universities be better off dividing themselves into first and second divisions (possibly with promotion and relegation)? Alternatively, the universities could try to find a whole new permanent source of income. The comprehensive student grant system in Britain seems absurdly generous to many of our European neighbours and yet the operation of the means test may deter some school leavers who would otherwise go on to tertiary education. A combination of scholarships, student loans, parental help, and 
vacation work supports the student population in many other countries where more school leavers than in Britain go on to university. These are only some solutions based on practice in other countries. What is certain is that our universities will get little public sympathy in the current economic climate if they simply hold out their begging bowls. As we said in January, ${ }^{5}$ the multiplicity of the academic talking shops makes procrastination easier than making decisions-but action is needed if disaster is to be averted.

This five-year crisis in academic medicine should be seen as a warning by the staff of the NHS. They, too, can see clear signs of ever-worsening financial problems. The Government's policy (on this and other issues) seems to depend on a conviction that an opinion repeated often enough becomes a fact. More money has to be found for health care in Britainbecause on objective measures the population of our country is not getting adequate medical treatment. How that money is found-from taxation, from health insurance, or from lotteries - is a political issue. The Government will be forced to face that issue only by public pressure.

The time may, indeed, have come for doctors to put the good of the community ahead of the needs of their individual patients. Data just published ${ }^{1}$ show that whereas West Germany, Italy, and France treat 70 patients per million population in the age range 55 to 64 for end-stage renal failure the NHS can manage only 22 per million; and in the over- 65 s our neighbours treat 50 per million against 3.5 by the NHS. When a clinician knows that his own patient cannot have some treatment or investigation which is available to most patients in Europe or the United States, his instinctive reaction is to tell the patient or the relatives that nothing more can be done. That is the wrong response. If he speaks out and says what the NHS ought to be providing but is failing to provide, his patient may be distressed. But, distressing as it may be for a patient and her family to know that treatment is possible but is not available, the alternative-pretending there is no suitable treatment-is surely a greater offence against medical morality.

\footnotetext{
1 South-east Thames and South-west Thames Regional Health Authorities. Renal services. Croydon and London: South-east Thames Regional
Health Authority and South-west Thames Regional Health Authority, 1982.

2 Steiner RE. New imaging techniques: their relation to conventional radiology. Br Med f $1982 ; \mathbf{2 8 4}: 1590-2$.

${ }^{3}$ Smith R. No apples for the teachers. Br Med $\mathcal{F} 1982 ; 284: 1965-6$.

4 University of London. London medical education-a new framework. Report of a Working Party on Medical and Dental Teaching Resources, chairman Lord Flowers. London: University of London, 1980.

5 Anonymous. Cuts and excellence. $\mathrm{Br} M e d \mathcal{F}$ 1982;284:294.
}

\section{Cataract surgery}

Improvements of surgical technique, instrumentation, and materials have reduced the frequency of many of the complications of cataract surgery, but ophthalmic surgeons still differ in their choice of operative technique. What have been the changes in recent years?

The microscope has given the surgeon a much more detailed view of the operative field, providing him with greater visual feedback and allowing, therefore, more manual control. The fine needles now used in cataract surgery hardly need tissue fixation in order to pass through the ocular structures. Accurate wound closure with smooth non-irritating materials makes the eye more comfortable in the early postoperative course and also much safer. Patients may be mobilised more quickly, return home earlier, and resume activities after a shorter convalescence.

A cataract can be removed with its capsule (intracapsular removal) or without its capsule (extracapsular removal). ${ }^{1}$ Both operations remove the fog, dazzle, distortion, and other discomforts suffered by the patient as cataract advances. Both have their advantages and disadvantages, and surgeons have their preference in particular cases. In both methods there have been developments which have made for safer surgery.

Intracapsular extraction exposes the face of the vitreous to damage, and this may lead to postoperative problems. The enzyme alpha-chymotrypsin, which acts on the suspensory ligament of the lens, makes the operation safer and easier. The lens itself can be held by capsule forceps, by suction, or by freezing with a cold probe at $-40^{\circ} \mathrm{C}$. The latter method is by far the safest, since it provides a grip not only on the lens capsule but also through it into the substance of the lens itself.

During recent years there has been a rebirth of enthusiasm for extracapsular extraction as refined by the use of new instruments. In the older method the extraction of the lens cortex was incomplete, causing irritation of the eye, an iritis, and sometimes a severe immune response. Thickening of the lens remnants might obstruct the pupil, and results were not as good as with the intracapsular method. This has now changed. Extracapsular extraction may now be performed through a much smaller incision, reducing the risk of some complications. The nucleus of the lens may be removed with a microcutter or by ultrasonic emulsification. The microscope allows the surgeon to see all the lens cortex in detail, pick it up piece by piece, and peel back to the equator of the lens in a wedge and then from the surface of the posterior capsule.

Several claims and counterclaims are being made about the merits of intracapsular and extracapsular extraction, ${ }^{2}$ but the final result and the total incidence of postoperative complications are much the same with both methods. Their expectation of success is high and the risk of serious complication low.

Postoperatively, spectacles give greatly improved visual acuity, but many problems remain, to which some patients can never adapt. The visual image is enlarged, the visual field limited, and the prismatic and peripheral aberrational effects require that the head is moved rather than the eyes. Judgment of distance is impaired, leading to clumsiness in performing simple tasks, and there is no prospect of binocular vision unless both eyes are in the same condition. Contact lenses overcome many of these problems, but most patients with cataracts are elderly and are slow to adapt and learn. Contact lenses designed for prolonged wear have helped some patients but have not proved fully satisfactory.

The ideal position for any optical correction is as close to the normal site of the lens as possible, and the insertion of an intraocular lens immediately after cataract extraction is now possible with an acceptable level of safety. It demands high surgical skill and a careful choice of method. Temporary loss of the anterior chamber or a small peripheral adhesion of the iris would probably not threaten the end result in orthodox cataract surgery, but when an intraocular lens has been inserted these complications are more important and may lead to irreversible damage to the corneal endothelium. Even momen tary contact can destroy thousands of endothelial cells on the posterior corneal surface.

Nevertheless, if patients are suitably selected and proper precautions are observed the incidence of complications with intraocular lens surgery should differ little from those of orthodox 